by the Minister of Health, the Home Office and Scotland Yard. What was to be done with these women? If they were put into the Services no one would associate with them and they could not be put behind barbed wire.

Another point was that the transference of documents was not being made out properly, especially for merchant seamen. A tremendous amount of work had been done to induce people to fill in these forms but the fact was that medical officers had seemed to hate putting pen to paper. For years he had worked for a standard of treatment for merchant seamen. He had had courses laid down; special cards had been issued; the League of Nations had recommended courses but this seemed to have had little effect.

Dr. Orpwood Price, in reply, thanked Col. Harrison for his talk but thought that the real trouble was money. There was not sufficient money to attract enough good candidates for this branch of Medicine.

As far as almoners were concerned he seemed to have brought a hornet's nest about his ears. If Dr. Curtis really had thought his remarks should not be published he (Dr. Curtis) would not have made such an onslaught on him. He thought his remarks should be published if only in order to obtain another point of view.

He thought that the Society, as suggested in his paper, should form a subcommittee to consider what should be done regarding a new deal for venereal diseases.

Dr. Burgess, also in reply, said that Col. Harrison referred to the fact that if the standard of V.D. training was raised to too high a level there would be great difficulty in filling all the appointments. His reply would be that if the scale of remuneration was raised the difficulty would be overcome.

Brig. Osmond had asked about the seventy-two persons who had attended voluntarily at the clinics. These were people concerning whom there had been one notification but they were not compulsory cases. He had had only five compulsory cases in the West Riding. The seventy-two had attended as the result of persuasive methods and he was unable to say how many were actually suffering from syphilis or gonorrhoea. Medical officers in charge of clinics were under no obligation to give this information to local authorities; they were compelled to give information on compulsory cases only.

With regard to the 130 hours' training the difficulty had been that local authorities had had the impression that a doctor who had spent 130 hours training in a large clinic automatically became a V.D. specialist; it was something which had been bound to arise when the minimum time standard had been fixed at 130 hours. It was an impression which should be corrected. He agreed that nurses should have theoretical and practical training in venereology; either this Society or the Ministry of Health could stimulate the General Nursing Council to make venereal disease a compulsory subject in the State Registration examination.

-With regard to the black marketing of the sulphonamide drugs he had known a clinic where the director had complained that his supplies of sulphathiazole were vanishing unaccountably. Thereupon he had set a trap and had found that an orderly had been taking the tablets and had been selling them to patients in the intermediate treatment department.

Col. Harrison had made it clear that persuasive methods did not lay local authorities open to actions for libel in cases under Regulation 33B. He wondered if the Ministry of Health could make this absolutely clear to town clerks because in the West Riding, although the administrative county took steps to persuade persons about whom there had been a single notification to attend a clinic, some of the county boroughs, of which there were eleven, did not. They just filed away the forms until the second notification turned up.

\title{
Canadian control of venereal disease
}

A national programme for the control of venereal diseases has recently been planned in Canada. The six measures adopted are the following. (1) Healthy, dignified education about venereal diseases. (2) Adequate facilities for the diagnosis and treatment of all patients having these diseases. (3) Charlatan and quack treatment of venereal disease to be suppressed. (4) Early and suitable prenatal care, including blood tests, for expectant mothers. This will help to prevent their babies being infected with venereal diseases. (5) General examination, with blood tests for syphilis, before marriage. (6) Effective measures for dealing with individuals and communities responsible for spreading these diseases. The National Defence Department and the Departments of Pensions and National Health and of Provincial Health are cooperating. Administrative machinery common to the Department of National Defence and the Federal Health Department has been set up. The Armed Forces through their respective medical services are providing up-to-date facilities for the prevention and cure of venereal diseases.-Venereal Disease Information, Washington, October, 1943.

\section{Statistics of cases reported under Regulation 33B}

Persons who have been found to be sources of venereal infection and who have been reported by at least two individuals undergoing treatment total 3,344 up to 30th September, 1943; of these two men and 150 women have undergone treatment. In addition, some 543 individuals out of 3,116 about whom only one report was sent to medical officers of health were persuaded, after an informal approach, to be examined and to undertake treatment.-Hansard, 4th February, $1944,1529$. 